\title{
In vivo whole-field blood velocity measurement techniques
}

\author{
Peter Vennemann $\cdot$ Ralph Lindken · Jerry Westerweel
}

Received: 1 September 2006/Revised: 1 February 2007 / Accepted: 2 February 2007/ Published online: 1 March 2007

(C) Springer-Verlag 2007

\begin{abstract}
In this article a number of whole-field blood velocity measurement techniques are concisely reviewed. We primarily focus on optical measurement techniques for in vivo applications, such as laser Doppler velocimetry (including time varying speckle), laser speckle contrast imaging and particle image velocimetry (including particle tracking). We also briefly describe nuclear magnetic resonance and ultrasound particle image velocimetry, two techniques that do not rely on optical access, but that are of importance to in vivo whole-field blood velocity measurement. Typical applications for whole-field methods are perfusion monitoring, the investigation of instantaneous blood flow patterns, the derivation of endothelial shear stress distributions from velocity fields, and the measurement of blood volume flow rates. These applications require individual treatment in terms of spatial and temporal resolution and number of measured velocity components. The requirements further differ for the investigation of macro-, meso-, and microscale blood flows. In this review we describe and classify those requirements and present techniques that satisfy them.
\end{abstract}

\section{Introduction}

The enormous scientific interest in blood circulation in general becomes obvious when we compare the long-term demands on the human circulatory system with that of

P. Vennemann $(\bowtie) \cdot$ R. Lindken $\cdot$ J. Westerweel

Laboratory for Aero- and Hydrodynamics,

Delft Technical University, Leeghwaterstraat 21,

NL-2628CA Delft, The Netherlands

e-mail: p.vennemann@tudelft.nl other mammals. Figure 1 visualizes the relation between life expectancy and the duration of the cardiac cycle in mammals (McMahon and Bonner 1983). This relation implies that the total number of heart beats (for mammals) is approximately constant (McMahon and Bonner 1983; Levine 1997). Humans take a rather exceptional position in the diagram. Evidently the human circulatory system is extraordinarily burdened. Therefore, it may not be surprising that cardiovascular diseases are presently the leading cause of death (Murray and Lopez 1997).

Especially atherosclerosis research requires the spatially resolved measurement of blood velocity distributions to determine the influence of endothelial shear stresses and instantaneous flow patterns. The measurement of shear stresses is also inevitable for researching the role of fluid-mechanical stimuli in cardiogenesis and angiogenesis. Spatially resolved velocity measurements can further be utilized for perfusion monitoring and the accurate determination of volume flow rates. These individual topics require different treatment in terms of spatial and temporal resolution and measured velocity components.

One of the less demanding blood flow measurements is skin perfusion monitoring. For many tasks, like the diagnosis of burn depth, it is sufficient to visualize the velocity distribution as a scalar map. The spatial resolution of the map might even be coarser than the vessel diameter of the microcirculation. Temporal resolution is generally not needed, as most capillary flows are almost stationary. This is the typical domain of various full-field laser Doppler techniques (Sect. 3.1) and laser speckle contrast imaging (Sect. 3.2.1). Higher spatial resolution is required for the evaluation of volume flow rates. The determination of the volume flow rate from the measurement of the mean velocity or the centerline velocity 


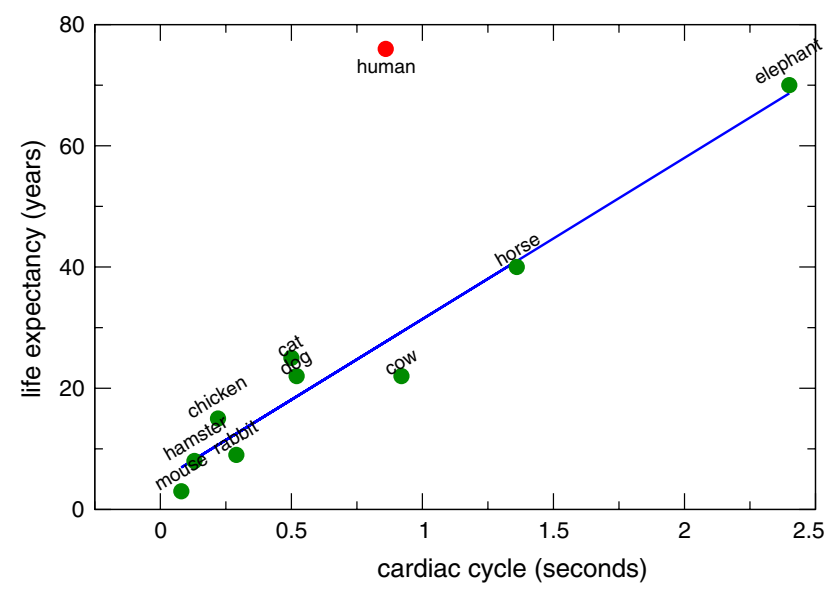

Fig. 1 Linear relationship between the life expectancy of mammals (in captivity) and the duration of their cardiac cyle at rest (data extracted from McMahon and Bonner 1983). Life expectancy and heart rate are related to the body mass in the same manner as standard metabolic rate is related to body mass (Kleiber's quarter power law, Kleiber 1932)

in a blood vessel and the assumption of a parabolic velocity profile might be an estimate of sufficient accuracy in many cases. Ultrasound Doppler velocimetry is a widespread technique for the measurement of blood velocities at a single point, a detailed review including an error estimation is given by Gill (1985). When the velocity profile is unknown (e.g. in bends, bifurcations, non-circular vessels, and near flow obstacles) it is necessary to measure the profile with high resolution over the diameter of the vessel (Cokelet et al. 1998; Merzkirch 2004). An extension of the laser Doppler technique addressing this problem is given in Sect. 3.1.3. In a simple geometry, the measurement of the main velocity component is for the most part sufficient. Nuclear Magnetic Resonance Imaging can be used for determining velocity profiles in larger vessels (Sect. 3.5). This technique is especially useful for blood vessels that are covered by thick layers of tissue. More complex geometries might require the measurement of two or even three velocity components. Pulsatile flows additionally require a temporal resolution that is at least half the period of the highest relevant harmonic (Nyquist 1928). A solution at lower spatial but high temporal resolution that is also useful for deep lying vessels, is offered by ultrasound particle image velocimetry (Sect. 3.4). The derivation of wall shear stress from the velocity gradients near the flow boundary demands a high spatial resolution that is significantly better than a blood cell-diameter. Here particle image velocimetry and particle tracking techniques are most suited (Sect. 3.3). Reneman et al. (2006) review the difficulties that are connected with the assessment of wall shear stress in vivo.
Some awareness about the specific problems associated with blood flow is essential for the correct interpretation of the measured velocity data. Therefore, a brief section about cardiovascular flow is preceding the section about the different measurement techniques. Cardiovascular flow differs from many laboratory and engineering applications by the complex geometry (Sect. 2.1), the complex fluid (Sect. 2.2), and the complex boundary conditions (Sect. 2.3).

\section{Cardiovascular flow}

\subsection{Geometry}

The geometry of the cardiovascular system is strongly three-dimensional (e.g. the heart and aortic arch) and involves multiple scales which range from the aorta (with a diameter of about $2 \mathrm{~cm}$ ) to the arteries and veins (with diameters in the millimeter range) to arterioles, venules, and capillaries with diameters that are much smaller than a millimeter (see Table 1). The flow ranges from strongly pulsatile (in the aorta and arteries) to nearly stationary in the smallest capillaries. The flow is primarily characterized by two dimensionless numbers: the Reynolds number $R e$ and Womersley number $\alpha$, defined as

$R e=\frac{d \bar{V} \rho}{\eta}$ and $\quad \alpha=d \sqrt{\frac{2 \pi f \rho}{\eta}}$

where $d$ is a characteristic length (e.g., the diameter of a blood vessel), $\bar{V}$ the bulk velocity, $\rho$ the density, $\eta$ the dynamic viscosity, and $f$ the characteristic frequency. In general the Reynolds number is below 2000 (Table 1), which implies that the flow in most blood vessels is laminar. For low Womersley numbers the pulsatile flow is dominated by viscous effects rather than momentum effects. The Reynolds number and Womersley number can be defined for the flow in blood vessels which have a cylindrical geometry, but for the constantly varying

Table 1 Reference values for mean velocity $\bar{V}$, diameter $d$ (Charm and Kurland 1974), shear rate $\dot{\gamma}$, Reynolds number Re, and Womersly number $\alpha$ in the human vascular network

\begin{tabular}{lllrll}
\hline Vessel & $\bar{V}(\mathrm{~m} / \mathrm{s})$ & $d(\mathrm{~mm})$ & $\dot{\gamma}\left(\mathrm{s}^{-1}\right)$ & $\operatorname{Re}(-)$ & $\alpha(-)$ \\
\hline Aorta & 0.4 & 25 & 130 & 2500 & 260 \\
Arteries & 0.45 & 4 & 900 & 450 & 40 \\
Arterioles & 0.05 & 0.05 & 8,000 & 0.5 & 0.5 \\
Capillaries & 0.001 & 0.008 & 1,000 & 0.002 & 0.1 \\
Venules & 0.002 & 0.02 & 800 & 0.01 & 0.2 \\
Veins & 0.1 & 5 & 160 & 125 & 50 \\
Vena cava & 0.38 & 30 & 100 & 2800 & 310 \\
\hline
\end{tabular}


geometry and flow patterns in the heart it is more difficult to define these numbers.

\subsection{Fluid mechanical properties of blood}

Blood is a complex fluid that consists of a continuous fluid, or plasma, containing complex molecules (e.g. proteins, nutrients, hormones) and larger particles (e.g. red and white blood cells, platelets). Among technically relevant fluids, blood exhibits the most intricate behavior. Blood as a whole reacts mechanically as well as chemically with its environment. At the same time the components of blood react mechanically and chemically with each other. The mechanically most relevant components of blood are plasma and red blood cells (erythrocytes).

Figure 2 shows photographs of unprocessed, human blood at a scale of $0.16 \mu \mathrm{m}$ per pixel. The left photo shows a layer of about $20 \mu \mathrm{m}$ thickness. The tendency of the erythrocytes to stick together in aggregates is clearly visible. Those aggregates are widely referred to as rouleaux, because of there resemblance with stacks of coins. The right photo shows erythrocytes in a layer of less than $8 \mu \mathrm{m}$ thickness. Their diameter ranges around $7 \mu \mathrm{m}$. The rim of the flat, bi-concave shaped cells has a thickness of about $2 \mu \mathrm{m}$. The volume fraction of erythrocytes (hematocrit) is about $45 \%$ but varies with age and gender (Schmidt and Thews 1987). The ability of erythrocytes to form aggregates and their high deformability are responsible for the non-Newtonian viscosity of blood (Chien 1970). Figure 3 illustrates this effect by comparing the shear dependent viscosity of normal blood with the viscosity of blood where the cells do not aggregate (addition of albumin) and blood with cells that can also not deform (hardened cells). The increased apparent viscosity of normal blood at very low shear rates is, therefore, attributed to the agglomeration of cells, while the lowered viscosity at high shear rates is attributed to the deformability of the cells (Chien 1970).

Blood contains a small number $\left(4 \times 10^{3}\right.$ to $10 \times 10^{3}$ per $\mu \mathrm{l}$ ) of white blood cells (leukocytes), that are an

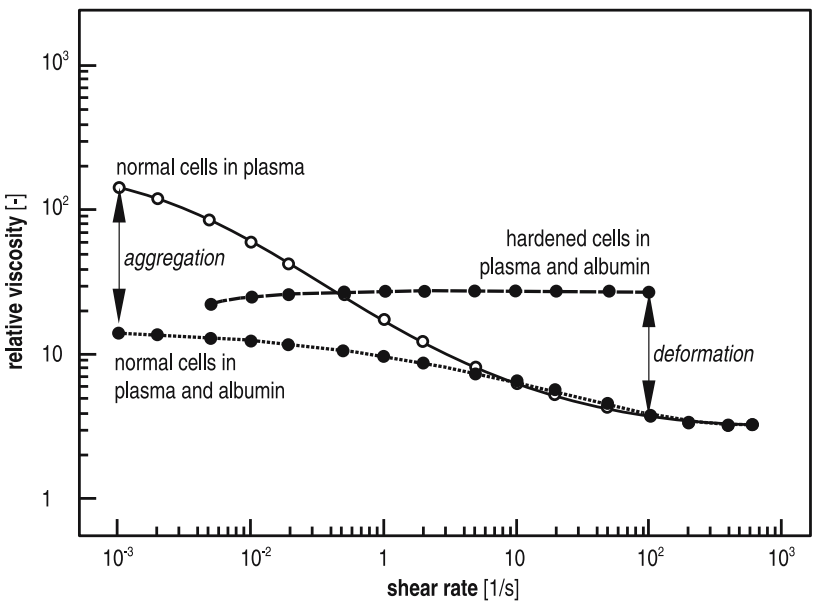

Fig. 3 Relation between viscosity and shear rate for human blood. The viscosity is normalized with the plasma viscosity of $1.2 \times 10^{-3} \mathrm{~Pa}$. The haematocrit is $45 \%$ in all experiments. The addition of $11 \%$ albumin prevents the adhesion of erythrocytes (data from Chien 1970)

essential part of the immune system (Schmidt and Thews 1987). Leukocytes are larger than erythrocytes. Of fluid mechanical interest is their ability to roll over and to stick to the surface of blood vessels (Ley 1993; Sperandio et al. 2006).

Another essential component of blood are platelets (thrombocytes). Thrombocytes have a length of 1-4 $\mu \mathrm{m}$ and a thickness of $0.5-0.75 \mu \mathrm{m}$ (Schmidt and Thews 1987). Because of their small size and large number $(150 \times$ $10^{3}$ to $350 \times 10^{3}$ per $\mu \mathrm{l}$ ) they can be used as tracer particles for velocity measurements (Slaaf et al. 1984; Tangelder et al. 1985, 1986, 1988). They are particularly useful for measurements in the plasma rich layer near the vessel wall. This flow regime is generally erythrocyte-depleted due to the Fåhraeus-Lindquist effect (Barbee and Cokelet 1971; Albrecht et al. 1979; Pries et al. 1992; Shul'man et al. 1995; Bishop et al. 2001b). This effect also indicates that the erythrocytes do not follow exactly the motion of the blood plasma, which implies that they may not always be suitable as "natural" tracer particles for blood flow
Fig. 2 Unprocessed human blood (courtesy of P.V.) seen through a light microscope $(\times 40$ magnification or $0.16 \mu \mathrm{m}$ per pixel). The left photograph shows a layer of about $20 \mu \mathrm{m}$ thickness. Rouleaux formation is clearly visible. The right photograph shows a layer of less than $8 \mu \mathrm{m}$ thickness
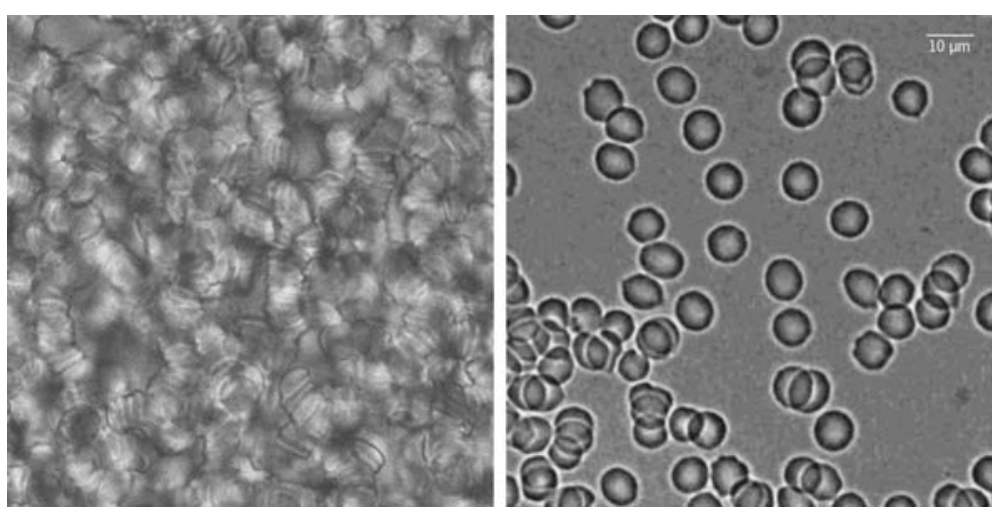
measurements. Uijttewaal et al. $(1993,1994)$ showed that platelets experience a reversed Fåhraeus-Lindquist effect and concentrate in the erythrocyte-depleted layer.

Plasma consists mainly of water. A mass fraction of about $8 \%$ of different proteins raises the viscosity of plasma to almost twice the viscosity of water (Harkness 1971). Among the plasma-proteins, fibrinogen can be of fluid mechanical relevance. The clotting-ability of blood rests on this protein that activates and attaches blood platelets (thrombocytes). Plasma contains a number of electrolytes. These are mainly the ions of dissolved sodium chloride that alone make up $96 \%$ of the osmotic pressure of about $745 \mathrm{kPa}$ (Schmidt and Thews 1987).

Reviews about hemorheology and hemodynamics appear regularly (Copley et al. 1942; Copley and Blair 1962; Wayland 1967; Bugliarello 1977; Liepsch 1986, Copley 1990; Liepsch 2002; Lipowsky 2005; Popel and Johnson 2005). The treatment of blood as a continuous or two-phase fluid and the consideration of non-Newtonian properties depends on the studied problem and the scale. At macro scale, when the ratio of blood cell size and characteristic length of the flow domain is small, one might treat blood as a liquid of continuous phase. Low shear rates in the center region of large vessels, however, lead to a radial viscosity gradient. This results in a flattened velocity profile, if compared to a Hagen-Poiseuille profile (Bishop et al. 2001a). Flow through intermediate blood vessels can be simplified further. Arterioles and venules are still much larger than blood cells. Typical shear rates range between 800 and $8,000 \mathrm{1} / \mathrm{s}$ and belong to the highest shear rates in the human vasculature (Charm and Kurland 1974) (Table 1). The low shear region in the center of the blood vessel is narrow, when compared to the typical size of erythrocyte aggregates. The radial viscosity gradient becomes less pronounced, the blood viscosity might even be assumed constant. Bishop et al. (2001a) measured parabolic blood velocity profiles in venules of 45-75 $\mu \mathrm{m}$ diameter when the shear rate is higher than $40 \mathrm{~s}^{-1}$. Charm and Kurland (1966), Charm et al. (1968), and Charm and Kurland (1974) suggest to treat blood as a Newtonian fluid when the dimensionless group $C /\left(\bar{V}^{2} \rho\right)$ is smaller than $5 \times 10^{-4}$, the cell hematocrit $\varphi$ is greater than 0.4 , and the vessel diameter $d$ is between 155 and 2,000 $\mu \mathrm{m}$. The yield stress of blood, $C$, is the critical stress that must be applied to start blood to flow. Values are published by Charm and Kurland (1967). Further, $\bar{V}$ is the mean velocity and $\rho$ the density. At small scale, when blood cells and flow domain diameter are of the same magnitude, blood flow is generally treated as two-phase flow. At even smaller scale (e.g., the erythrocyte depleted layer near the vessel wall) we might treat blood cells and blood plasma domain separately. For the smallest capillaries the flow becomes irregular and is determined by the transport of individual blood cells. A lubrication theory for the movement of single erythrocytes through capillaries that are smaller in diameter than the cells is developed by Feng and Weinbaum (2000).

\subsection{Boundary conditions}

The transport of blood through the cardiovascular system also includes complex and scale-dependent boundary conditions. Not only are we dealing with instationary or pulsatile flow, but also with flows through tubes with deformable elastic walls. The wall deformation interacts with the flow. A detailed discussion of the fluid-structure interaction as a result of pulsatile flow in flexible tubes would fall outside the scope of the present paper, and for a further discussion of this topic we refer to Zamir and Ritman (2000). At small scales the walls of the blood vessels have a very complex structure. The vessels are lined with endothelial cells that are covered with a gel-like permeable layer of sugar-like molecules, which is referred to as the glycocalyx layer (van den Berg et al. 2003). The glycocalyx layer has an estimated thickness between 10 and $400 \mathrm{~nm}$ (Fig. 4). The function of the glycocalyx is unknown, but it may be involved in the regulation of the total blood flow and protect the endothelial cells against high flow shear rates that may rupture the cells. The glycocalyx may also play a role in reducing the friction of the transport of $\mathrm{RBC}$ through very small capillaries (Feng and Weinbaum 2000).

\section{Measurement techniques}

This review is restricted to methods that measure velocities (scalar and vectorial) directly. This excludes perfusion measurement techniques that merely allow conclusions on

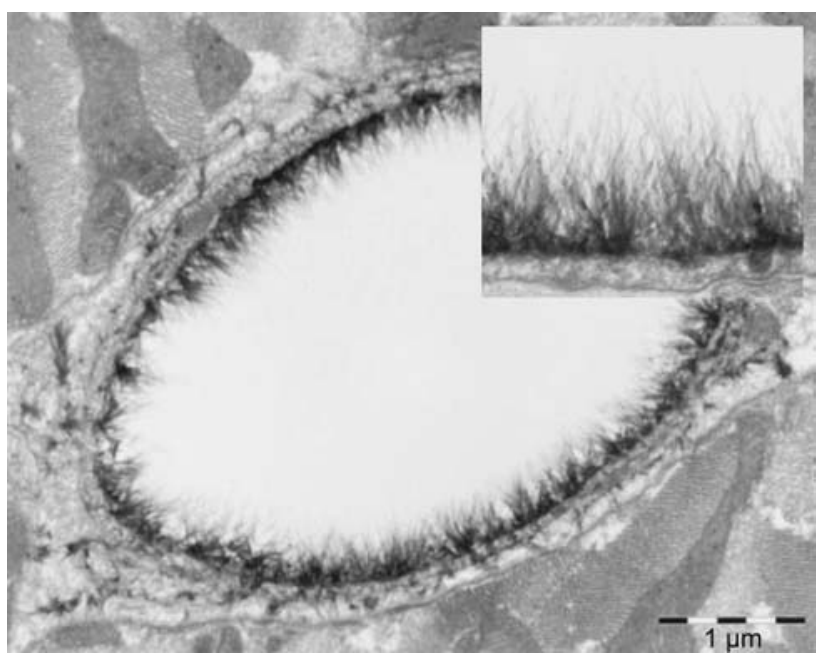

Fig. 4 Electronmicrographs of the glycocalyx layer in a rat left ventricular myocardial capillary (figure adapted from van den Berg et al. 2003) 
mean and time averaged velocities. These would be, for example, radionuclide perfusion imaging such as single photon emission computed tomography and positron emission tomography that are reviewed by Lodge et al. (2005) and Cuocolo et al. (2005). Positron emission tomography is also part of a review of Zhao et al. (2002). Ultrasonic and electromagnetic point velocity and volume flow rate measurement techniques as well as a microsphere reference sample method are reviewed by Tabrizchi and Pugsley (2000). Pulsed Doppler ultrasound systems enable the noninvasive measurement of instantaneous flow profiles along the ultrasonic beam. For this technique we refer to Hoeks et al. (1981), Gill (1985), and Brands et al. (1995).

\subsection{Laser Doppler velocimetry}

Laser Doppler velocimetry, in its original form, is a single point measurement technique with extraordinary temporal resolution. A detailed review of this technique was published by Tropea (1995). Systems that measure up to three velocity components are commercially available. Laser Doppler Velocimetry for spatial measurements is primarily implemented in three ways: scanning (Sect. 3.1.1), simultaneous single point measurements with multiple probes (Sect. 3.1.2), and differentiation of tracer particle position within the measurement volume (Sect. 3.1.3). Full field laser Doppler systems generally provide only one velocity component.

The measurement principle of laser Doppler velocimetry is based on the optical Doppler effect: if a light source (or a light scattering tracer particle) is moved into the direction of a light-detector, the frequency of the reflected light is increased. If the light source moves away, the frequency is decreased. In practice this frequency shift is very small $(10-100 \mathrm{kHz})$ when compared to the high frequencies of light $(100 \mathrm{THz})$ and impractical to measure directly. The frequency shifted light is, therefore, combined with a nonshifted reference beam. The resulting beat frequency equals the frequency shift and is directly related to the velocity of the light scatterer.

Combining the scattered light and the reference beam takes effort and is sensitive to errors. The different light paths might be affected by changing refraction indices due to temperature variations, for example. Therefore, most laser Doppler systems are implemented in such a way that both laser beams intersect at an angle. The intersection volume defines the measurement location. A tracer particle passing this volume is illuminated from two different directions. The frequency shift of the reflected light is different for the two laser sources. The resulting beat depends on the angle of the two laser beams and the tracer velocity perpendicular to the axis, $z$, that bisects the angle, $\theta$, between the beams.
A different way of looking at the concept of the two intersecting beams is to study the interference pattern within the measurement volume. The wave-fronts of the laser beams form interference fringes parallel to the optical axis of the focusing lens system (represented by the Moiré pattern in Fig. 5). When a tracer particle moves through the dark and bright spaces of the fringe system, it will reflect light at a frequency that depends on the fringe spacing and the particle velocity component, $v$ perpendicular to the fringes. Both perceptions lead to an identical relationship between particle velocity and measured frequency-shift, $\Delta f$ :

$v=\frac{\lambda}{2 \cdot \sin (\theta / 2)} \cdot \Delta f$

Here, $\lambda$ is the wavelength of the incident light. The penetration depth of light in tissue depends on its wavelength. Near infrared light $(\lambda \approx 1 \mu \mathrm{m})$ penetrates several $\mathrm{mm}$, red light $(\lambda \approx 650 \mathrm{~nm})$ up to about $2 \mathrm{~mm}$ and green light $(\lambda \approx$ $540 \mathrm{~nm}$ ) hardly at all (Briers 2001).

It should be mentioned that real laser beams are slightly diverging when they leave the laser cavity. This is related to the curved (focusing) cavity mirrors at the ends of the laser rod (Hecht 2002). Lenses focus the diverging beams in the measurement spot to reduce the size of the measurement volume. The Moiré pattern in Fig. 8 represents a more realistic fringe system than the one in Fig. 5. The smallest diameter of the laser beam is called the beam waist. The distance over which the cross section of the beam doubles is referred to as the Rayleigh length (Hecht 2002). In Sect. 3.1.3 the presence of a short Rayleigh length is exploited for measuring a velocity profile.

\subsubsection{Full-field approach by means of scanning}

Essex and Byrne (1991) described a scanning laser Doppler velocimetry system with continuously moving laser beams. The scanned measurement data is usually visualized as an image with color-coded velocity information. The relative motion between laser and tissue, however, can give rise to

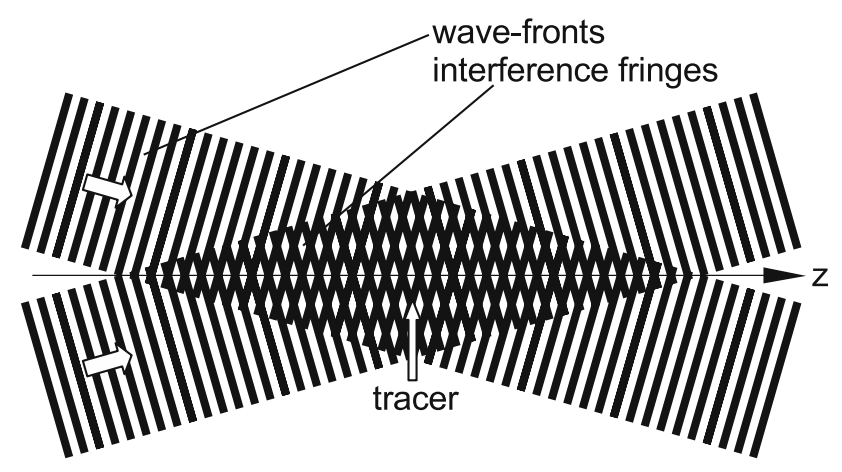

Fig. 5 Interference pattern of two crossing laser beams 
significant artifacts. Wardell et al. (1993) circumvented this problem by using stepping motors for moving the scanning mirror. The scan time was 4 min for 4,096 image points. Meanwhile, commercial scanning laser Doppler velocimetry systems (laser Doppler imagers/flowmeters) are available that, for example, map skin perfusion over areas of $50 \mathrm{~cm} \times 50 \mathrm{~cm}$ with $256 \times 256$ pixel resolution in about 5 min (Moor Instruments Ltd.). Retina perfusion can be measured with a spatial resolution of up to $10 \mu \mathrm{m}$ and a temporal resolution of $2 \mathrm{~s}$ for a scan of $256 \times 64$ pixel (Heidelberg Engineering $\mathrm{GmbH}$ ) (Michelson et al. 1995). The scanning devices lack a reference beam. Instead, Doppler shifted light from moving blood cells beat with reflected light from stationary tissue. Because of the low spatial resolution, there will be several blood cells with different velocities in the measurement volume. This results in a frequency distribution around a frequency representing the mean velocity rather than a single beat frequency.

Scanning laser Doppler velocimetry has become a standard tool in diagnostics. Figure 6 shows a laser Doppler scan. The number of publications is enormous. Briers (2001) identified various fields of applications in his review. One of the most important applications might be the diagnosis of burn depth. Pape (2001) published an audit about the use of laser Doppler imaging in the assessment of burns of intermediate depth. Superficial burns show an inflammatory response, which is indicated by high perfusion. This diagnosis can be used to distinguish superficial burns from deeper burns that need surgical treatment.

Basically similar to scanning laser Doppler velocimetry is the time-varying speckle technique (Sect. 3.2.2).

\subsubsection{Full-field approach: multi-probes}

Serov et al. $(2002,2005)$ avoid scanning by replacing the widely used avalanche photo detector by a complementary metal oxide semiconductor (CMOS) image sensor. In contrast to charge coupled device (CCD) sensors, some CMOS sensors allow the continuous conversion of photocurrent into output voltage. The Doppler shift ranges typically between 0 and $20 \mathrm{kHz}$ for the microcirculation. To attain a corresponding sampling rate, the area of interest had to be reduced to $64 \times 8$ pixel. A perfusion map of $256 \times$ 256 pixel could be obtained by sampling 128 sub-windows one after the other. The repetition rate for measuring the full area is $90 \mathrm{~s}$ inclusive signal processing (mainly determined by the FFT) and screen display. Results are shown in Fig. 7.

\subsubsection{Profile approach: differentiation of tracer position}

Czarske (2001) introduced a system that differentiates between the positions of the tracer particles within the measurement volume. The set-up measures the velocity profile within the elongated laser Doppler measurement volume, along the optical axis of the focusing lens

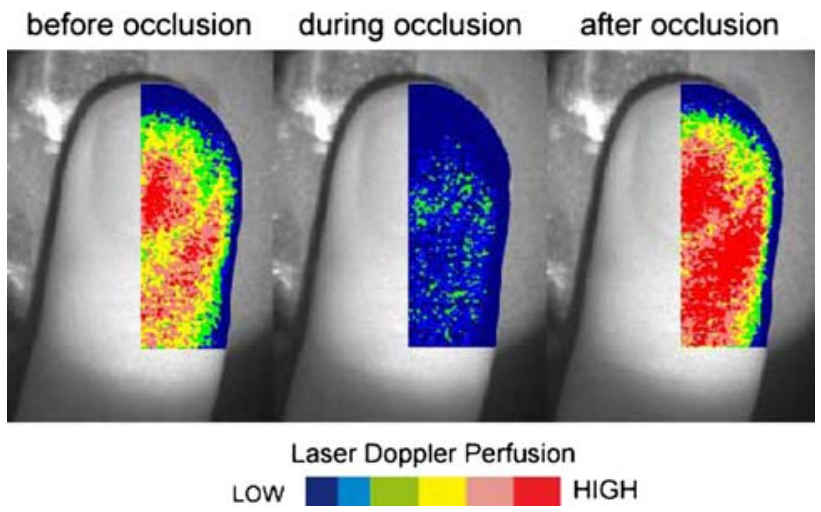

Fig. 7 Multi-probe Doppler perfusion images of the finger-tip obtained before, during, and after ligation of the upper arm (figure from Serov et al. (2005))
Fig. 6 Laser Doppler scan of a hand visualizing the Raynaud's disease phenomenon, a perfusion disorder related to temperature changes. The left scan shows the baseline measurement, the right scan shows the hand after cold water immersion (scans are kindly provided by Moor Instruments Ltd.)

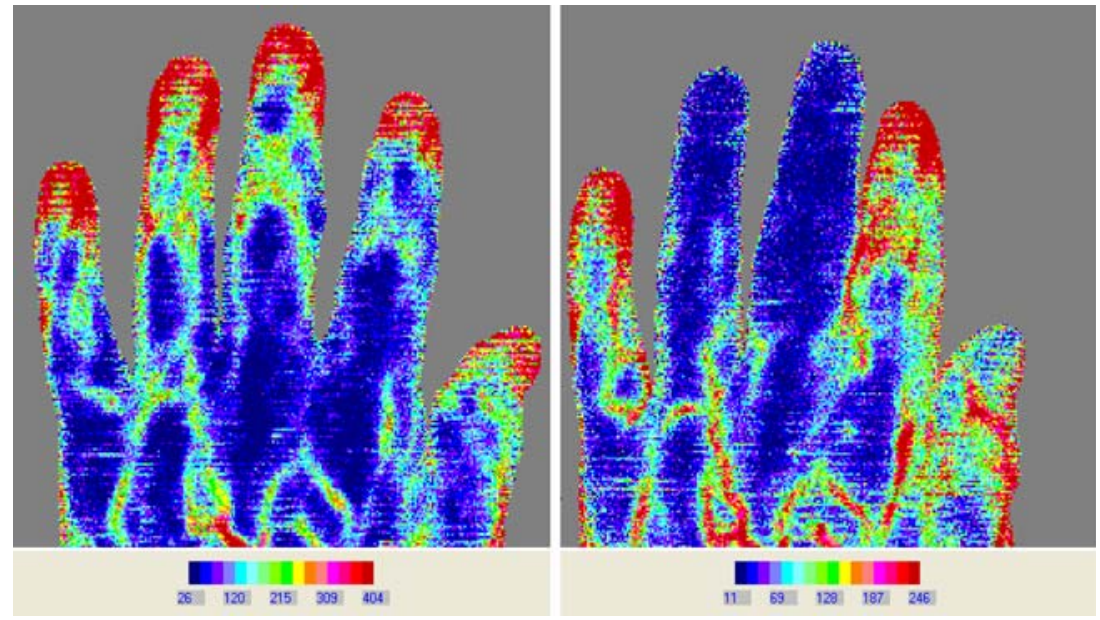


system. The system exploits the curvature of the Gaussian laser wave fronts (see also Sect. 3.1). Because of this curvature, the distance of the interference fringes varies along the optical axis (Fig. 8). To determine the position of a tracer particle in the measurement volume, a second pair of laser beams with a different frequency (color) is added to the set-up. Due to (intended) chromatic aberration of the focusing lens system, the beam waists of both beam pairs are shifted longitudinally with respect to each other. In this way, one of the fringe systems in the measurement volume is convergent, the other one divergent. A particle that passes through the measurement volume will thus reflect two burst signals of different frequency. The quotient of the two monochromatic burst frequencies, $f_{i}$, equals the quotient of the different interference fringe distances, $d_{i}$, at this position. This quotient is unique for the position along the optical axis. The particle position, $z$, is then determined by means of a calibration function $\varphi$ :

$z=\varphi\left(\frac{f_{1}(z)}{f_{2}(z)}\right)$

Once the position of the particle is determined, one of the monochromatic burst signals is used to determine the velocity. The length of the measurement volume is adjusted to the individual application $(5 \mathrm{~mm}$, Czarske et al. 2002; $1.2 \mathrm{~mm}$, Czarske et al. 2001; $0.7 \mathrm{~mm}$, Buettner et al. 2005). The spatial resolution is reported to reach the submicrometer domain (Buettner et al. 2005). Alternative methods of generating two suitable fringe systems are reported by Buettner and Czarske (2003) and Shirai et al. (2006). The two velocity components perpendicular to the optical axis can be measured by aligning two fringe systems orthogonally to each other. Additionally, the axial velocity component can be determined from the temporal frequency variation of the Doppler burst signal Buettner

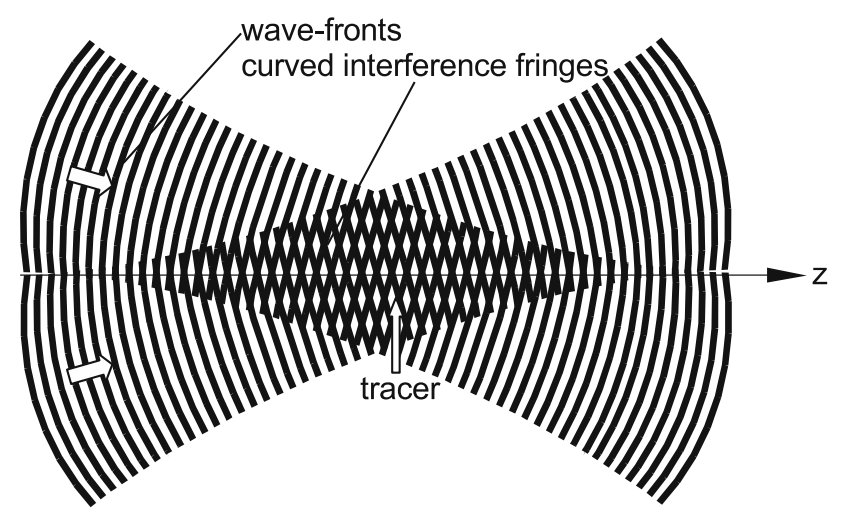

Fig. 8 Interference pattern of two Gaussian laser beams-waists and Czarske (2006). The technique has not yet been applied to in vivo blood flow.

\subsection{Laser speckle techniques}

Laser speckle is a grainy, stationary interference pattern (Merzkirch 1987). It is produced when coherent light is scattered at a diffuse surface or a number of individual scatterers (like particles in a fluid). Interfering wavelets of different optical pathlenghts fill the surrounding space with a random pattern (Goodman 2000). Individual speckles are very small close to the diffuse surface and grow in size at larger distance. When scatterers move in a uniform manner, the speckle pattern moves at the same rate. Small relative displacements of scattering particles slightly change the speckle pattern. Large relative displacements alter the pattern entirely.

\subsubsection{Laser speckle contrast imaging}

Laser speckle contrast imaging is based on so-called image speckle. This occurs when a larger area is illuminated by a laser and projected on an image plane. A time-integrated image of stationary particles shows a speckle pattern of high contrast. Moving particles reduce the contrast due to the averaging of the instationary speckle pattern over time. An equation can be deduced that links flow velocity to reduction in speckle contrast (Fercher and Briers 1981). Speckle contrast is reduced by particle movement in any direction. This makes the technique sensitive for motion parallel as well as perpendicular to the measurement plane. The speckle pattern change due to motion along the line-of-sight is such that a relative movement of half a wavelength causes a full cycle of intensity change. The sensitivity to in-plane motion is significantly weaker, because it is only determined by the size of the speckle pattern (Briers 1996). The directional difference in sensitivity is the main reason why the relationship between flow velocity and contrast reduction must be deduced for different types of velocity distributions. Therefore, the type of velocity distribution must be known a priori (Briers et al. 1999).

Briers et al. (1999) advanced the development of laser speckle contrast imaging and concisely reviewed the technique. Figure 9 shows a laser speckle evaluation. At present, laser speckle contrast imaging has developed into a standard perfusion measurement technique for animal models (Yuan et al. 2005) that can be combined with other techniques to monitor blood flow, hemoglobin concentration and oxygenation simultaneously (Dunn et al. 2003). Zhao et al. (2002) included laser speckle imaging in a review about skin blood flow imaging. Latest effort aims on the reduction of noise (Voelker et al. 2005). 


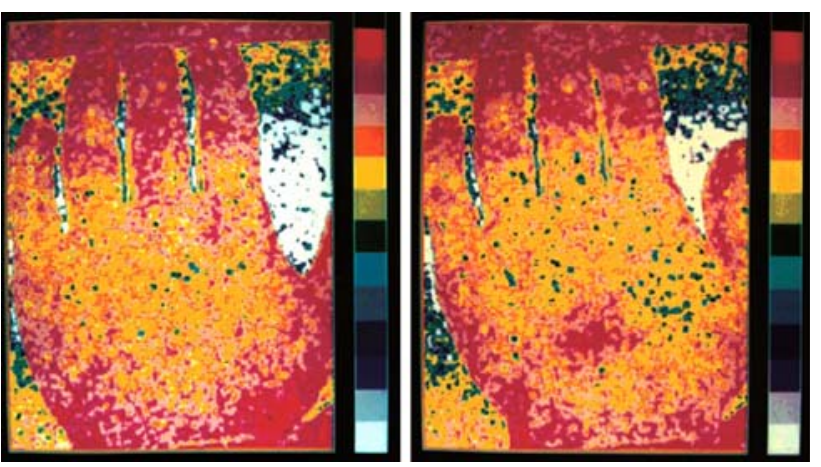

Fig. 9 Laser speckle contrast image before (left) and after (right) gently scratching the back of a hand (figure from Briers 2001)

\subsubsection{Time-varying speckle}

Time-varying speckle is based on the evaluation of temporal statistics of speckle fluctuations at a single point. In comparison to laser speckle contrast imaging (Sect. 3.2.1), that is based on image speckle, so-called far-field speckle is utilized. A collimated laser beam illuminates a small point in the flow. Light from all points within this area interferes in the image plane and forms the speckle pattern. When the scatterers move, individual speckles at a fixed position fluctuate. The frequency spectrum of these fluctuations can be related to velocity information.

Briers (1996) showed that the interference-based perception of far-field speckle can be interpreted in terms of the Doppler effect. To show the equivalence of the Doppler and the interferometric explanation, he considers a Michelson interferometer (Fig. 10). When the mirror in the measurement arm of the interferometer is moved, a small detector in the detection plane recognizes a temporal intensity fluctuation. This fluctuation can be interpreted as the beat of the reference beam and the light that is reflected by the moving mirror. The frequency of the light that comes from the moving mirror is altered due to the Doppler effect. The detected intensity fluctuation can also be explained by the variation of the optical path length, without considering the Doppler effect. The optical path-length of

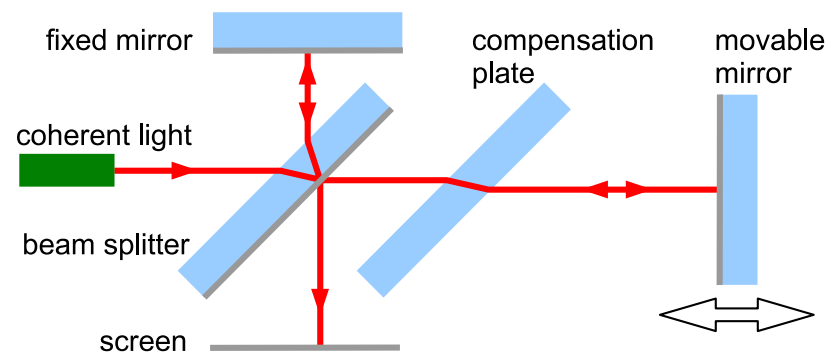

Fig. 10 Michelson interferometer the beam that is reflected by the moving mirror is continuously altered due to motion. Depending on the actual mirror position constructive or destructive interference is recorded at the detector. The relation between intensity fluctuation frequency and mirror velocity can be shown to be identical in both cases.

The main difference between laser Doppler velocimetry and time-varying speckle is the absence of a separate reference beam. A Doppler spectrum is still present when there is interference of scattered light from particles with different velocities (different beat frequencies). This spectrum, however, just provides information about the variation of velocities in the measurement volume rather than the mean velocity. When there are stationary tracers present in the measurement volume, the variation of velocities is a measure for the mean velocity. It now becomes obvious that this technique is basically identical to the laser Doppler imager (Sect. 3.1.1). Aizu and Asakura (1999) reviewed different statistical methods to extract the mean blood cell velocity from speckle fluctuations.

\subsection{Particle image velocimetry}

Particle image velocimetry relies on the visualization of flow by means of small tracer particles. In general, the movement of the particles is recorded in two consecutive, digital images. The displacement of the particles in the second image, relative to the position of the particles in the first image, divided by the time delay between the exposures, is a measure for the velocity of the fluid. The displacement of the particles is calculated by means of a two-dimensional cross-correlation (Keane and Adrian 1992). Therefore, a small interrogation window of the first image is correlated with different sections of the second image until the maximum correlation magnitude between the image areas is found. This position is the most probable displacement of the particle pattern in the interrogation window (Keane and Adrian 1990, 1991; Adrian 1991; Raffel et al. 1998). The local velocity is approximated by dividing the displacement of the particle pattern by the given time difference between the two images. In contrast to speckle methods it is not the grade of decorrelation that contains the velocity information. Decorrelation only occurs due to particles leaving the measurement volume or due to shear within the interrogation area, but not due to the movement itself. Particle image velocimetry, therefore, does not rely on the correlation peak height but rather on the correlation peak position to obtain the velocity magnitude.

For typical macroscale particle image velocimetry applications, a two-dimensional measurement plane is formed by illuminating a thin plane of the flow with a narrow laser light sheet, whereas for microscale applications 
the strongly limited depth-of-focus of the microscope objective is used to sample a thin plane in which the particles are sharply imaged (Santiago et al. 1998; Meinhart et al. 1999, 2000a; Olsen and Adrian 2000; Bourdon et al. 2004a, b).

Closely related to particle image velocimetry are particle tracking techniques. Here the movement of individual particles is tracked manually or by appropriate computer programs. In contrast to particle image velocimetry, particle tracking velocimetry requires the distance between the tracer particles to be larger than the displacement (Westerweel 1997). Otherwise it is not possible to unambiguously identify matching particle pairs. This restriction limits the resolution of pure particle tracking velocimetry. The combination of a pre particle image velocimetry evaluation and sub interrogation window particle tracking, however, reaches utmost spatial resolution (Keane et al. 1995), only exceeded by single pixel ensemble correlation methods (Westerweel et al. 2004). Ji and Danuser (2005) and Danuser (2005) use an ensemble correlation method like introduced by Meinhart et al. (2000b) in combination with sub-interrogation-window particle tracking to measure actin flow in an epithelial cell at a spatial resolution in the order of $100 \mathrm{~nm}$.

Another closely related term is optical flow. In general, optical flow algorithms (Lucas and Kanade 1981; Horn and Schunck 1981), aim to calculate the shift of intensity gradients between two images for every pixel. The displacement of a single pixel cannot be calculated independently of neighboring pixels (Horn and Schunck 1981). This leads to comparable spatial averaging effects as in particle image velocimetry, where blocks of pixels are correlated with each other.

Single camera set-ups measure the two velocity components parallel to the image plane. Two camera (stereo) systems can also measure the out-of-plane velocity component (Arroyo and Greated 1991; Prasad 2000; Lindken et al. 2006).

Several research groups used particle image velocimetry or related particle tracking techniques to study blood flow. The probably first quantitative, optical measurement of erythrocyte velocities in vivo is reported by Basler (1918). Basler used a self-made light conductor for back-illumination of a straight blood vessel in the sartorius muscle of a frog. A microscope was used to project the erythrocyte movement onto a film that was driven perpendicular to the erythrocyte movement (Fig. 11). The erythrocytes produce streaks on the film. The angle of the streaks relative to the film is determined by the speed of the film and by the velocity of the erythrocytes. Developments based on this technique are discussed by Monro (1965). Wayland (1967) developed a technique that is based on the passage time of erythrocytes between two lines of photosensitive elements. The signals of two elements are correlated with each other, respectively, to determine the velocity profile of erythrocytes over the blood vessel diameter (Gaehtgens et al. 1971). Spatial averaging, however, leads to strongly blunted velocity profiles (Baker and Wayland 1974). SchmidSchoenbein and Zweifach (1975) used a high speed film camera to analyze the erythrocyte motion in arterioles, venules, and postcapillaries in the omentum of a rabbit. A series of more than 100 instantaneous cell velocity profiles
Fig. 11 The set-up published by Basler (1918) to measure erythrocyte velocity profiles. The light of an arc lamp is focused into the light guide for back illumination of the blood vessel

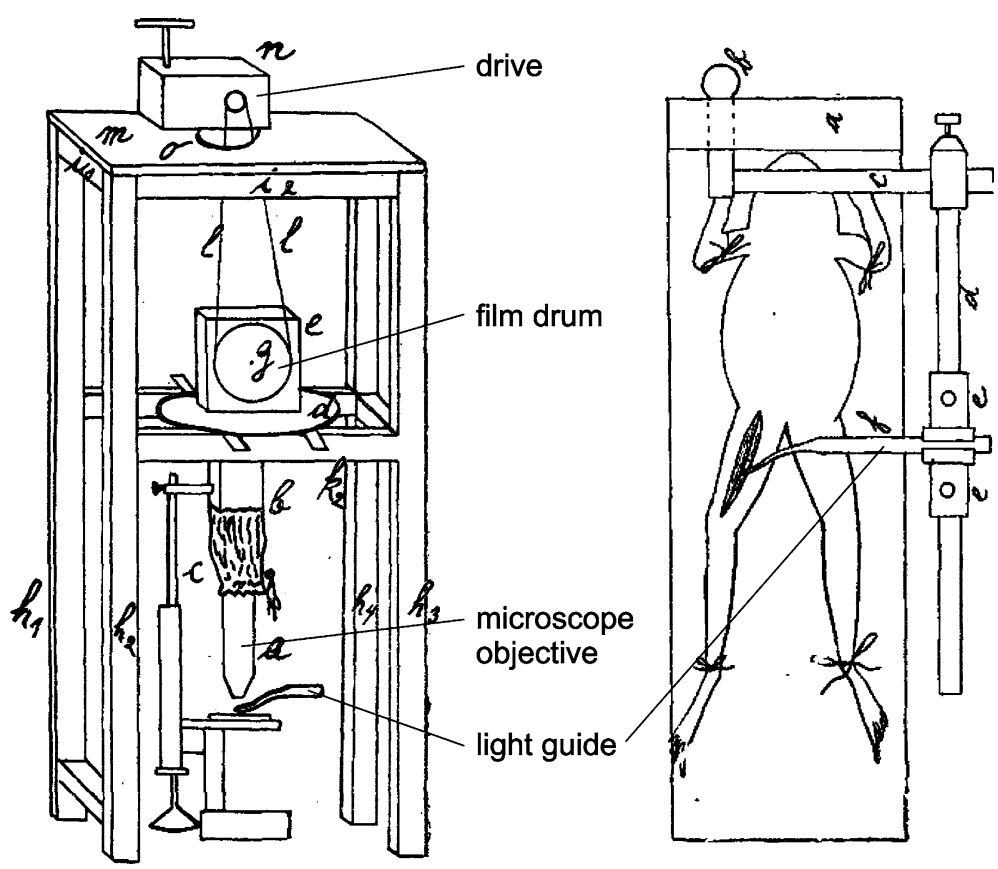


were determined as shown in Fig. 12. Tangelder et al. (1986) enhanced the spatial resolution of the tracking technique by labeling blood platelets with a fluorescent dye to measure flow velocities in arterioles of the rabbit mesentery (17-32 $\mu \mathrm{m}$ diameter). Dual flash video images were used to capture the platelet motion. The velocity profiles were assembled by a number of individual measurements at different radial positions of the vessel. The illumination flashes were triggered my means of an electrocardiogram (ECG). Smith et al. (2003) and Long et al. (2004) adapted this technique by using artificial, fluorescent tracer particles of $470 \mathrm{~nm}$ diameter to further enhance the spatial resolution. The velocity gradient in the near wall region of a mouse cremaster muscle venule could be estimated by manually tracking the movement of tracer particles at irregular distances from the flow boundary. A typical particle tracking result is shown in Fig. 13. Velocity data can be acquired at high spatial resolution by this method. The manual evaluation is highly dependent on the operator and limits the amount of processable data. Sub-pixel accuracy is not achieved.

Singh and Prakash (1994) used optical flow algorithms to determine velocity profiles in $180 \mu \mathrm{m}$ vessels of frogs and mice. Hitt et a (1996) applied a correlation technique to video images of the venous flow in the hamster cremaster muscle. Tsukada et al. (2000), Sugii et al. (2002a, b), and Jeong et al. (2007) used particle image velocimetry to measure red blood cell velocity profiles in mesentery

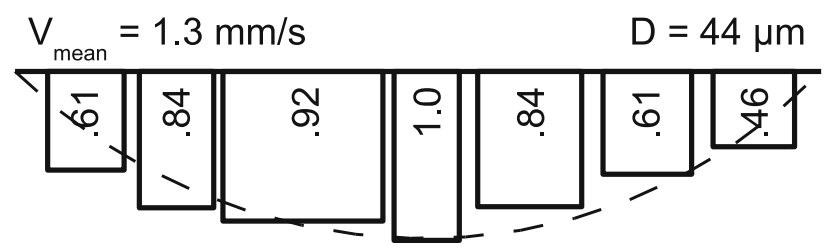

Fig. 12 Red cell velocity profile in a venule of the rabbit omentum. The image is reproduced from Schmid-Schoenbein and Zweifach (1975)

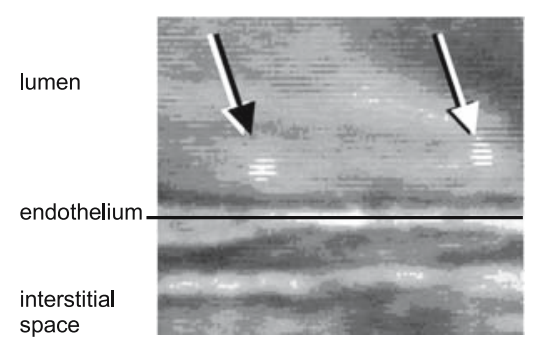

Fig. 13 Particle tracking in a mouse cremaster muscle venule (figure adapted from Smith et al. 2003). Left Double stroboscopic image of a single microsphere in a venule of $21 \mu \mathrm{m}$ diameter. The black arrow points to the first, the white arrow to the second image of the sphere. vessels of rats (Fig. 14). Hove et al. (2003) and Hove (2004) followed the course of small groups of erythrocytes through the heart of a zebrafish embryo (Fig. 15). These works have in common that they use erythrocytes as tracer

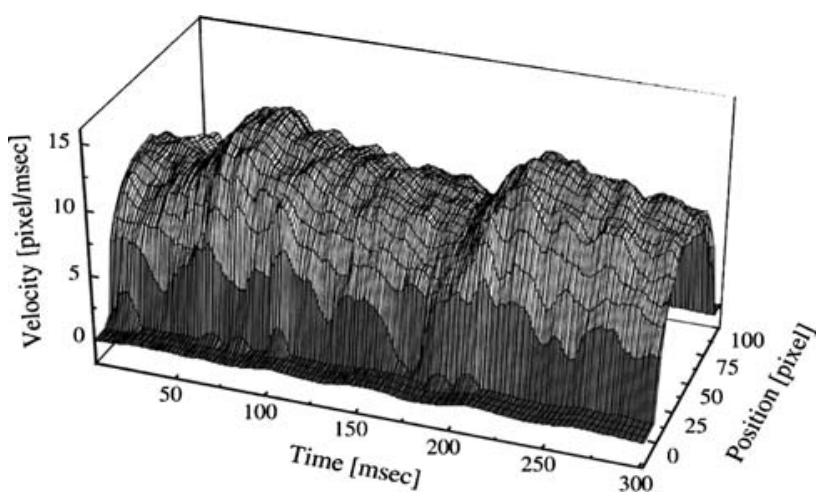

Fig. 14 Time series of cross sectional blood velocity profiles obtained by particle image velocimetry in an arteriole in the rat mesentery (figure from Sugii et al. 2002b). The vessel is about $25 \mu \mathrm{m}$ wide. Erythrocytes were used as tracer particles. A high speed camera $(512 \times 512$ pixel, 1,000 frames per second $)$ was used for image acquisition

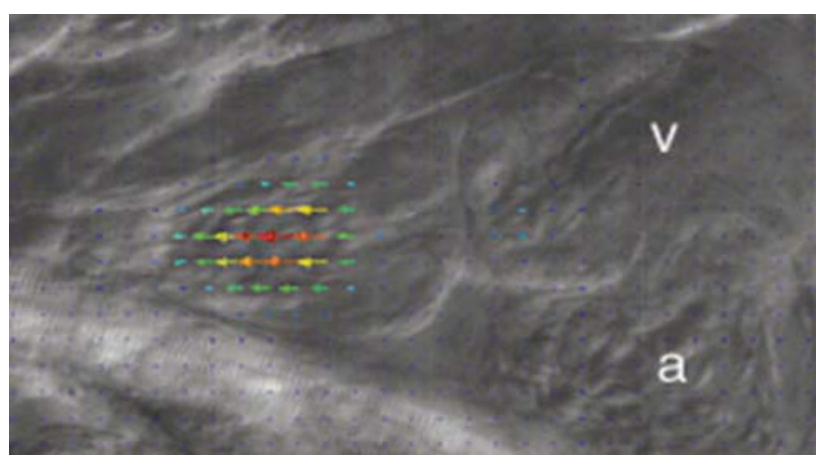

Fig. 15 Particle Image velocimetry field in the bulbus arteriosus of a zebrafish embryo during systole ( $a$ atrium; $v$ ventricle). The flow domain is about $50 \mu \mathrm{m}$ wide. The images were acquired at $256 \times 256$ pixels in real time. The figure is modified from Hove et al. (2003)

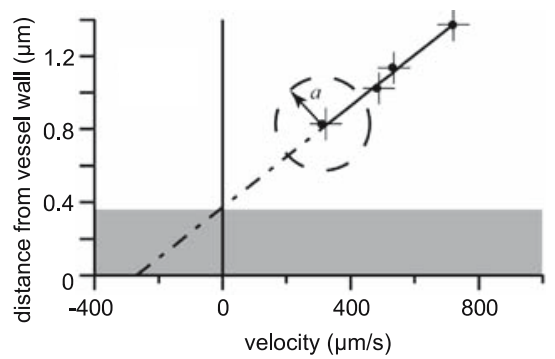

Right Cumulative particle tracking data in a vessel of $32.8 \mu \mathrm{m}$ diameter. The velocity becomes zero at a finite distance above the vessel wall, indicating the presence of a glycocalyx layer (Fig. 4) 
particles, so the physiological disturbance is limited to a minimum. The measured erythrocyte velocity, however, might differ from the plasma velocity (Sect. 2.2). Conclusions on the wall shear stress distribution are, therefore, difficult to deduce. Debaene et al. (2005) showed how to derive wall shear rate fields in artificial vessels from a single particle tracking measurement. They determined the depth position of the tracer particles from their brightness in a hazy fluid.

Vennemann et al. (2006a) used fluorescent liposomes (Woodle and Lasic 1992; Allen 1996; Singh et al. 2001) of $400 \mathrm{~nm}$ diameter to resolve the velocity distribution in the beating heart of a chicken embryo. The use of small tracer particles that also penetrate the red cell-depleted layer close to the wall enables the automated determination of wall shear stress. Sufficient spatial resolution, however, has not been achieved due to low seeding density. Measurements were carried out at nine different cardiac phase angles. Figure 16 shows the measured velocity distribution in the developing ventricle at its maximum dilation. The velocity has a maximum magnitude of $26 \mathrm{~mm} / \mathrm{s}$ and peaks off-center at the side of the inner curvature wall. The eccentricity of the flow profile can be explained by the low Dean number, $D n=\delta^{1 / 2} R e$, of the flow. The curvature of a curved tube, $\delta$, is defined as the ratio of tube and coil radii, $a / R$. The Dean number is proportional to the ratio of centrifugal forces and viscous forces. Centrifugal forces shift the velocity peak to the outer curvature wall. Viscous forces lead to a homogeneous pressure distribution over the cross-section of the vessel. This results in a higher pressure gradient along the inner curvature wall and shifts the peak velocity to the inner curvature wall (Dean 1927, 1928; van Dyke 1978; Hung et al. 1979, 1980; Wang and
Bassingthwaighte 2003). The curvature of the heart-coil is about $1 / 2$ for the case shown in Fig. 16. The Reynolds number is about unity. Three-dimensional information can be acquired by extending the measurements to parallel planes (Vennemann et al. 2006b).

\subsection{Ultrasound particle image velocimetry}

Particle image velocimetry is not restricted to optically acquired images. Lin et al. (2003) used ultrasonic imaging to measure the velocity distribution in the left ventricle of a pig. Kim et al. (2004a, b); Zheng et al. (2005) and Zheng et al. (2006) determined flow profiles in artificial models of arteries and in a rotating flow apparatus. In contrast to optical imaging, an ultrasound image is composed by scanning the field of interest. Scattering tracers, in general small gas bubbles, reflect echoes. The intensity of the echo depends on the reflective property of the tracers. The time between sound emission and detection (time of flight) is used to determine the scanning depth. The time difference between two images in optical particle image velocimetry is replaced by the time difference between identical beam positions in two successive echo scans. Due to high seeding densities and small tracer diameters, when compared to the utilized wavelength, ultra sound images rather show a speckle pattern than single particle images. The speckle pattern, however, stays fairly stable and moves with the flow (Lin et al. 2003). Figure 17 shows an exemplary result. The spatial resolution of ultrasound particle image velocimetry is effectively about three orders of magnitude lower than with optically acquired images (Table 2). Zheng et al. (2006) report a spatial resolution of up to $0.4 \mathrm{~mm}$ and a temporal resolution of up to $0.5 \mathrm{~ms}$.
Fig. 16 Blood velocity distribution in the developing ventricle of a chicken embryo after three days of incubation (Vennemann et al. 2006a). The radius of loop curvature is about $200 \mu \mathrm{m}$. Location and orientation of the measurement plane is indicated in the scanning electron micrograph from Maenner (2000). The interrogation window size is 20 $\times 20 \mu \mathrm{m}$

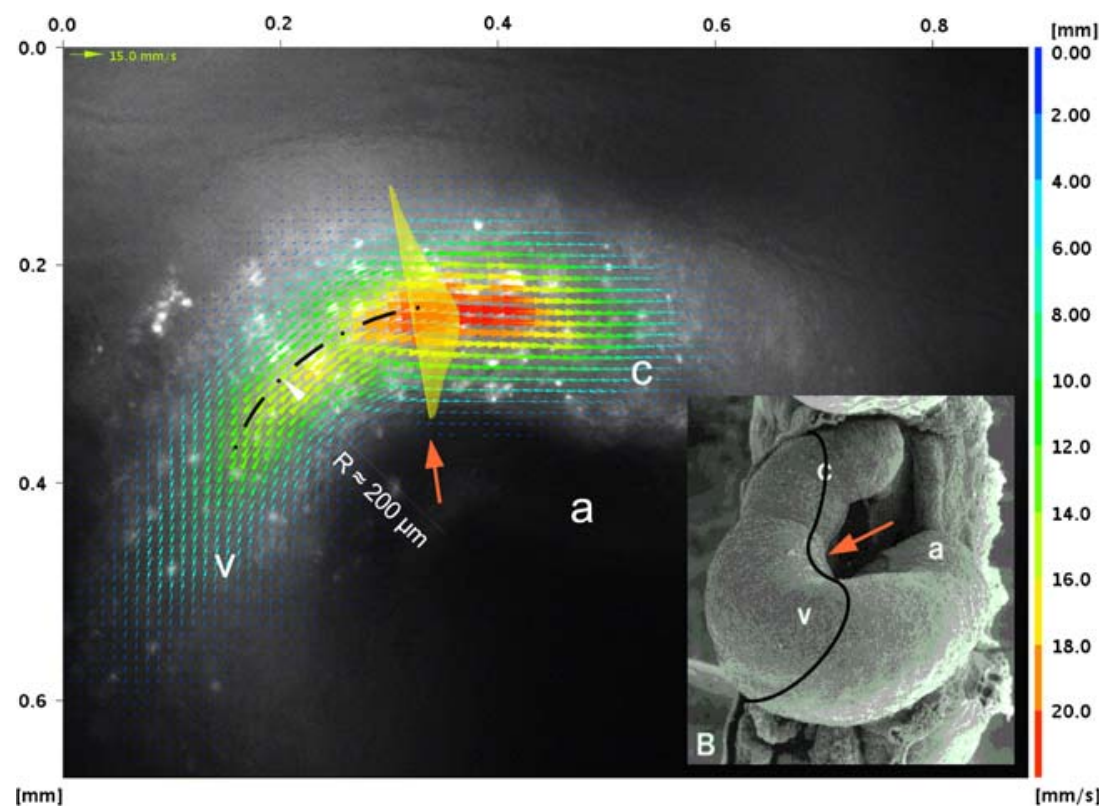


Fig. 17 Instantaneous ultrasound particle image velocimetry field in a rotating flow chamber (figure from Zheng et al. 2006)

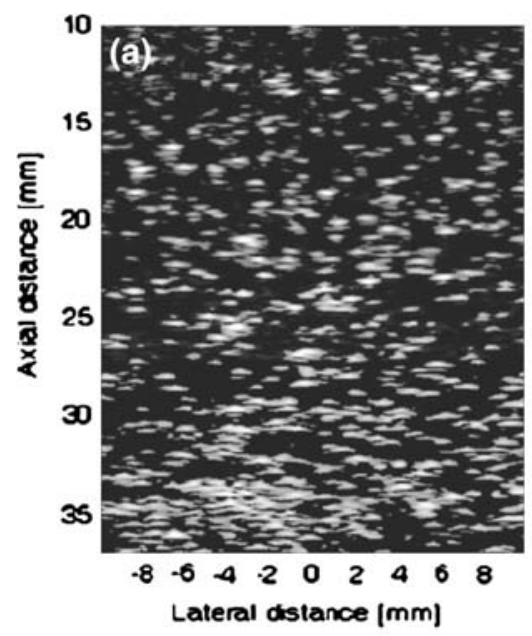

Table 2 Spatial and temporal resolution of in vivo full field blood velocity measurement techniques

\begin{tabular}{|c|c|c|c|c|}
\hline Method & Velocity components & $\begin{array}{l}\text { Spatial } \\
\text { resolution }(\mu \mathrm{m})\end{array}$ & $\begin{array}{l}\text { Measurement } \\
\text { duration (s) }\end{array}$ & Remarks \\
\hline Scanning laser Doppler & 1 & $10^{1} \mathrm{a}$ & $10^{0 \mathrm{~b}}$ & Standard diagnostics tool ${ }^{\mathrm{c}}$ \\
\hline Multi-probe laser Doppler & 1 & $10^{2 \mathrm{~d}}$ & $10^{2 \mathrm{e}}$ & Under development \\
\hline Profile laser Doppler & Standard $1^{\mathrm{f}}$, up to $3^{\mathrm{g}}$ & $10^{-1 \mathrm{~h}}$ & $10^{-3}$ & Under development \\
\hline Laser speckle contrast imaging & 1 & $10^{2} \mathrm{i}$ & $10^{-3}$ & Standard research tool for animal models \\
\hline Particle image velocimetry & Standard 2, up to $3^{\mathrm{k}}$ & $10^{-11}$ & $10^{-3}$ & Used in animal research \\
\hline Ultrasound particle image velocimetry & 2 & $10^{2 \mathrm{~m}}$ & $10^{-2 \mathrm{n}}$ & Used in animal research \\
\hline nuclear magnetic resonance imaging & Standard 1 , up to $3^{\circ}$ & $10^{2} \mathrm{p}$ & $10^{-2 \mathrm{q}}$ & Used in human research \\
\hline
\end{tabular}

\footnotetext{
${ }^{a}$ Retina perfusion measurements (Michelson et al. 1995)

${ }^{\mathrm{b}}$ For a $256 \times 64$ pixel area (Michelson et al. 1995)

c Briers (2001) and Pape et al. (2001)

${ }^{\mathrm{d}}$ Typical value for skin perfusion measurements. Systems are rather optimized for large imaging areas

${ }^{\text {e }}$ For a $256 \times 256$ pixel area inclusive data processing (Serov et al. 2005)

${ }^{\mathrm{f}}$ Czarske et al. (2002)

g Two components: Buettner and Czarske (2006). Three components introduced at the GALA Fachtagung 2006, Göttingen

h Buettner et al. (2005)

i Typical value for skin perfusion measurements

j Yuan et al. (2005)

k Three components can be measured with a two camera set-up Arroyo and Greated (1991)

${ }^{1}$ Smith et al. (2003)

${ }^{m}$ Zheng et al. (2006). Limited by the wavelength of ultrasound

${ }^{\mathrm{n}}$ Zheng et al. (2006)

${ }^{\circ}$ Markl et al. (2003)

p Bauer et al. (2001)

${ }^{\mathrm{q}}$ Per slice (Markl et al. 2003; Nezafat et al. 2005)
}

\subsection{Nuclear magnetic resonance imaging}

Nucleons have an angular momentum which leads to a quantized magnetic momentum or spin. In case of a hydrogen atom the nucleus is composed of a single (unpaired) proton. The magnetic moment is thus not counterbalanced. The potential energy of the magnetic momentum in an homogeneous, external magnetic field depends on the direction of the momentum. The potential energy is minimized when momentum and external field vectors point into the same direction and is maximized when they point into opposite directions. In case of the 
hydrogen nucleus, quantum mechanics permits just two possible orientations for the magnetic momentum: parallel and anti parallel with the outer magnetic field. The magnetic momentum of a hydrogen atom of low potential energy (parallel momentum vector and field vector) can be flipped into the high energy state (anti parallel vectors) by absorbing a photon of exactly the missing energy difference. Flipping a nuclear spin into this excited state is called nuclear magnetic resonance.The nucleus flips back into its normal state by emitting a photon. The frequency of this photon depends on the energy difference between the normal and the excited state which is determined by the strength of the outer magnetic field.

Hydrogen atoms are usually bound into molecules. The atoms in the immediate vicinity of a hydrogen atom interfere with the outer magnetic field and in this way change the energy difference between normal and excited state. The frequency of a resonance photon can, therefore, identify different chemical environments.

In nuclear magnetic resonance tomography, a second, inhomogeneous magnetic field is superimposed on the homogeneous magnetic field. The inhomogeneous field is shaped in a way that small resonance frequency bands can be assigned to a specific volume element of the measured object.

First investigations to exploit the nuclear magnetic resonance technique for measuring blood velocities date back to Singer (1959). Blood flow influences the nuclear magnetic resonance signal in several ways. The signal from fast flowing blood, for example, vanishes. This is explained by the displacement of the protons between excitation and detection and is referred to as spin wash-out. This effect can be exploited for velocity measurements by measuring the signal amplitude at varying time periods between excitation and detection (Singer and Crooks 1983). A wash-out curve is produced that can be related to the flow velocity.

Phase velocity cine magnetic resonance imaging exploits the phase shift of radio waves emitted by hydrogen in flowing blood (Powell and Geva 2000). Photons emitted by stationary tissue, in contrast, show no phase shift. The magnitude of the phase shift can be related to the flow velocity. The velocity component perpendicular to the measurement plane and the direction of the flow is determined. Measurements in orthogonal planes allow for the determination of all three velocity components (Markl et al. 2003). Frydrychowicz et al. (2006a, b) quantify the three dimensional flow in a Dacron graft repair (Fig. 18) and show the hydrydynamic influence of pathological geometric alterations of the thoracic aorta (Frydrychowicz et al. 2007).

Numerous other techniques for extracting flow velocity information from nuclear magnetic resonance imaging are

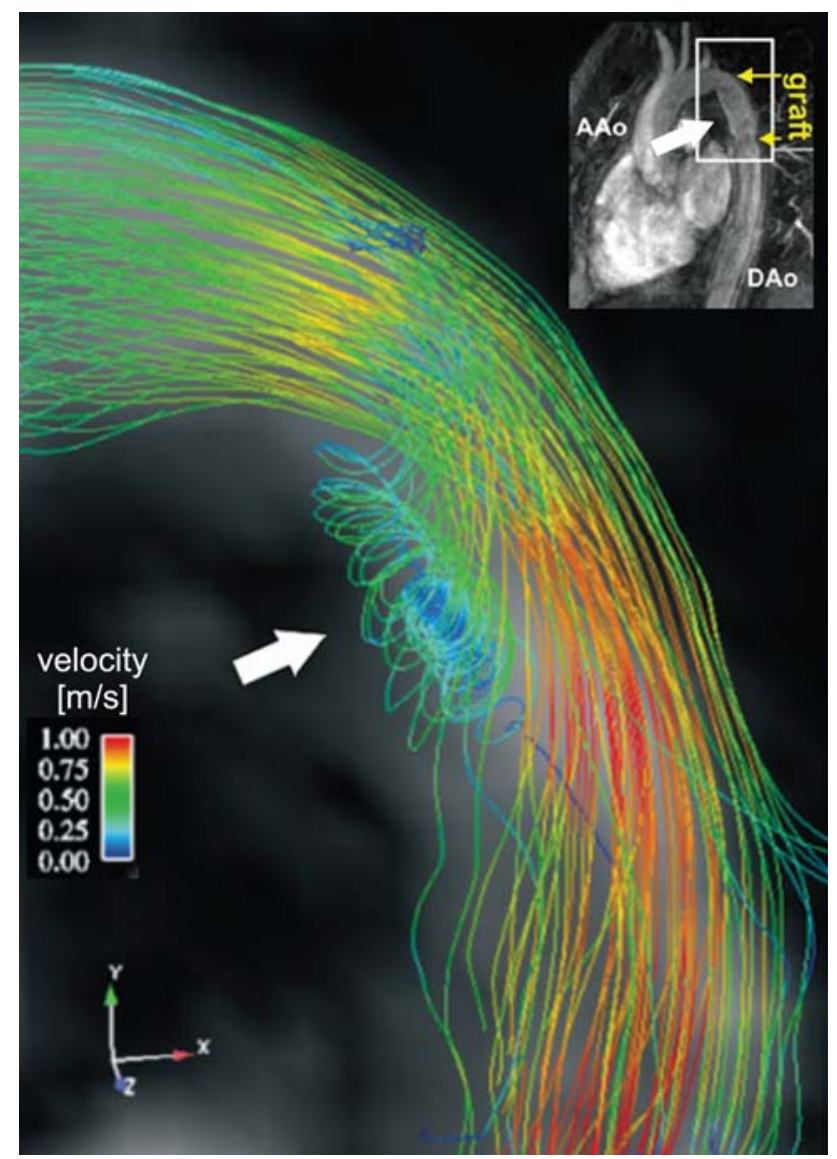

Fig. 18 Stream lines of systolic blood flow and vortex formation in an aortic Dacron graft repair (figure adapted from Frydrychowicz et al. 2006b)

reviewed by Smith (1990). Bradley and Waluch (1985) describe the effect of different flow phenomena on standard magnetic resonance images. Bauer et al. (2001) demonstrated myocardial perfusion measurements in isolated rat hearts at a spatial resolution of $140 \times 140 \times 1,500 \mu \mathrm{m}$ and a temporal resolution of $40 \mathrm{~s}$. Cuocolo et al. (2005) review the application of magnetic resonance imaging on the visualization of myocardial perfusion. Magnetic resonance imaging can also be used for the visualization of skin blood flow (Zhao et al. 2002).

\section{Conclusions}

Basically three principles of full-field velocity measurement exist that are suitable for monitoring capillary flow (optical access presumed): laser Doppler velocimetry (including time-varying speckle), laser speckle contrast imaging and particle image velocimetry (including particle tracking). Laser Doppler imaging and time-varying speckle imply low temporal resolution due to scanning. The multiprobes approach (Sect. 3.1.2) can principally enhance the 
temporal resolution, but cannot sample typical heart rates, yet. The profile approach (Sect. 3.1.3) might be used for time resolved volume flow rate measurements in microvessels. Particle image velocimetry and particle tracking velocimetry allow the determination of vectorial velocities at a spatial resolution that is high enough for accurate wall shear stress measurements. Video rate or high speed imaging enables the temporal resolution of typical heart rates.

In addition we consider two alternative full-field methods for blood flow measurements that do not rely on optical accessibility: nuclear magnetic resonance imaging and ultrasound particle image velocimetry. Consequently, these are methods that allow the non-invasive investigation of blood flow in deeper tissue layers. The spatial resolution of both techniques is limited due to the utilized wavelengths. The application is, therefore, restricted to the measurements of macro- and intermediate-scale blood flows.

Table 2 concisely summarizes the reviewed methods in terms of spatial and temporal resolution. The table serves as an overview rather than a comparison, because most of the discussed measurement methods are rather complementary. The treated methods cover three distinct application ranges with almost no overlap: (1) Laser Doppler imaging and speckle methods compete in the field of skin and retina perfusion imaging. (2) Particle image velocimetry and particle tracking techniques cover research in blood flow at small scales and high spatial resolution. (3) Ultrasound particle image velocimetry and magnetic resonance imaging compete in the field of flow measurements in the heart and in larger and intermediate blood vessels. These three application ranges define different technical boundary conditions. Particle image velocimetry and particle tracking techniques are developed to satisfy the demands of biomedical researchers. Determining parameters are basically spatial and temporal resolution. Perfusion imaging systems based on laser Doppler and speckle techniques are designed as a diagnostics tool. Safety and ease of use are the most important parameters. Nuclear magnetic resonance and ultrasound imaging systems are readily available in most hospitals and are already approved for human use. Velocity measurement capabilities are basically implemented as an additional feature.

The reviewed measurement techniques leave a gap in the application range. Large scale internal flows can be quantified as well as superficial microscale flows. The flow through the small blood vessels of the muscles, the inner organs, and the connecting tissue, however, remains immeasurable. (If we do not consider indirect measurement methods like radionuclide perfusion imaging.) Another gap of about six orders of magnitude can be observed between the wavelengths of the electromagnetic spectra that are utilized by the discussed measurement techniques. This gap is bounded by the radio waves on the one side and the visible spectrum on the other side. The unused microwave and infra-red spectra might provide a good trade-off between resolution and penetration depth in future technologies (e.g. terahertz imaging).

Acknowledgments We would like to thank those who contributed directly or indirectly to this manuscript: K.T. Kiger (University of Maryland, Mechanical Engineering), B.P. Hierck, R.E. Poelmann, B.C.W. Groenendijk (Leiden University Medical Center, Anatomy and Embryology), T.L.M. ten Hagen (Erasmus University Medical Center, Experimental Surgical Oncology), N.T.C Ursem (Erasmus University Medical Center, Obstetrics and Gynecology), R. Krams (Erasmus University Medical Center, Thoraxcenter), H. Vink (Maastricht University, Cardiovascular Research Institute), and R. Reneman (Cardiovascular Research Institute Maastricht). We are indebted to the late Frans Nieuwstadt who inspired the authors. P. Vennemann received financial support from the Dutch Technology Foundation (STW) (project number DSF.5695).

\section{References}

Adrian RJ (1991) Particle-imaging techniques for experimental fluid mechanics. Annu Rev Fluid Mech 23:261-304

Aizu Y, Asakura T (1999) Coherent opticel techniques for diagnostics of retinal blood flow. J Biomed Opt 4(1):61-75

Albrecht KH, Gaehtgens P, Pries A, Heuser M (1979) The Fahraeus effect in narrow capillaries (i.d. 3.3 to 11.0 micron). Microvasc Res 18(1):33-47

Allen TM (1996) Liposomal drug delivery. Curr Opin Colloid Interface Sci 1:645-651

Arroyo MP, Greated CA (1991) Stereoscopic particle image velocimetry. Meas Sci Technol 2:1181-1186

Baker M, Wayland H (1974) On-line volume flow rate and velocity profile measurement for blood in microvessels. Microvasc Res 7(1):131-143

Barbee JH, Cokelet GR (1971) The Fahraeus effect. Microvasc Res $3(1): 6-16$

Basler A (1918) Über die Blutbewegung in den Kapillaren. Pflugers Arch 171(1):134-145

Bauer WR, Hiller KH, Galuppo P, Neubauer S, Köpke J, Haase A, Waller C, Ertl G (2001) Fast high-resolution magnetic resonance imaging demonstrates fractality of myocardial perfusion in microscopic dimensions. Circ Res 88(3):340-346

van den Berg BM, Vink H, Spaan JAE (2003) The endothelial glycocalyx protects against myocardial edema. Circ Res 92(6):592-594

Bishop JJ, Nance PR, Popel AS, Intaglietta M, Johnson PC (2001a) Effect of erythrocyte aggregation on velocity profiles in venules. Am J Physiol Heart Circ Physiol 280(1):H222-H236

Bishop JJ, Popel AS, Intaglietta M, Johnson PC (2001b) Effects of erythrocyte aggregation and venous network geometry on red blood cell axial migration. Am J Physiol Heart Circ Physiol 281(2):H939-H950

Bourdon CJ, Olsen MG, Gorby AD (2004a) Power-filter technique for modifying depth of correlation in micro PIV experiments. Exp Fluids 37:263-271

Bourdon CJ, Olsen MG, Gorby AD (2004b) Validation of an analytical solution for depth of correlation in microscopic particle image velocimetry. Meas Sci Technol 15:318-327

Bradley WG, Waluch V (1985) Blood flow: magnetic resonance imaging. Radiology 154(2):443-450 
Brands PJ, Hoeks AP, Hofstra L, Reneman RS (1995) A noninvasive method to estimate wall shear rate using ultrasound. Ultrasound Med Biol 21(2):171-185

Briers JD (1996) Laser Doppler and time-varying speckle: a reconciliation. J Opt Soc Am A 13(2):345-350

Briers JD (2001) Laser Doppler, speckle and related techniques for blood perfusion mapping and imaging. Physiol Meas 22(4):R3566

Briers JD, Richards G, He XW (1999) Capillary blood flow monitoring using laser speckle contrast analysis. J Biomed Opt 4(1):164-175

Bugliarello G (1977) Biofluidmechanics: quo vadimus? Ann Biomed Eng 5(3):209-247

Büttner L, Czarske J (2003) Spatial resolving laser doppler velocity profile sensor using slightly tilted fringe systems and phase evaluation. Meas Sci Technol 14:2111-2120

Büttner L, Czarske J (2006) Determination of the axial velocity component by a laser-doppler velocity profile sensor. J Opt Soc Am A 23(2):444-454

Büttner L, Czarske J, Knuppertz H (2005) Laser-Doppler velocity profile sensor with submicrometer spatial resolution that employs fiber optics and a diffractive lens. Appl Opt 44(12):2274-2280

Charm SE, Kurland GS (1966) On the significance of the Reynolds Number in blood flow. Biorheology 3(3):163-164

Charm SE, Kurland GS (1967) Static method for determining blood yield stress. Nature 216(120):1121-1123

Charm SE, Kurland GS (1974) Blood flow and microcirculation. Wiley, New York

Charm SE, Kurland GS, Brown SL (1968) The influence of radial distribution and marginal plasma layer on the flow of red cell suspensions. Biorheology 5(1):15-43

Chien S (1970) Shear dependence of effective cell volume as a determinant of blood viscosity. Science 168:977-979

Cokelet GR, Pries AR, Kiani MF (1998) Observations on the accuracy of photometric techniques used to measure some in vivo microvascular blood flow parameters. Microcirculation $5(1): 61-70$

Copley AL (1990) Fluid mechanics and biorheology. Biorheology 27(1):3-19

Copley AL, Blair GWS (1962) Hemorheology. An introduction. Bibl Haematol 13:6-23

Copley AL, Krchma LC, Whitney ME (1942) Humoral rheology. J Gen Physiol 26:49-64

Cuocolo A, Acampa W, Imbriaco M, Luca ND, Iovino GL, Salvatore M (2005) The many ways to myocardial perfusion imaging. Q J Nucl Med Mol Imaging 49(1):4-18

Czarske J (2001) Laser Doppler velocity profile sensor using a chromatic coding. Meas Sci Technol 12:52-57

Czarske J, an T Razik LB, Müller H (2002) Boundary layer velocity measurements by a laser doppler profile sensor with micrometre spatial resolution. Meas Sci Techol 13:1979-1989

Danuser G (2005) Coupling the dynamics of two actin networks-new views on the mechanics of cell protrusion. Biochem Soc Trans 33(Pt 6):1250-1253

Dean WR (1927) Note on the motion of a fluid in a curved pipe. Philos Mag 4(20):208-223

Dean WR (1928) The stream-line motion of fluid in a curved pipe. Philos Mag 5(30):673-695

Debaene P, Kertzscher U, Goubergrits L, Affeld K (2005) Visualization of wall shear flow. J Vis 8(4):305-313

Dunn AK, Devor A, Bolay H, Andermann ML, Moskowitz MA, Dale AM, Boas DA (2003) Simultaneous imaging of total cerebral hemoglobin concentration, oxygenation, and blood flow during functional activation. Opt Lett 28(1):28-30 van Dyke M (1978) Extended Stokes series: laminar flow through a loosely coiled pipe. J Fluid Mech 86:129-145

Essex TJ, Byrne PO (1991) A laser Doppler scanner for imaging blood flow in skin. J Biomed Eng 13(3):189-194

Feng J, Weinbaum S (2000) Lubrication theory in highly compressible porous media: the mechanics of skiing, from red cells to humans. J Fluid Mech 422:281-317

Fercher AF, Briers JD (1981) Flow visualization by means of singleexposure speckle photography. Opt Commun 37(5):326-330

Frydrychowicz A, Weigang E, Harloff A, Beyersdorf F, Hennig J, Langer M, Markl M (2006a) Images in cardiovascular medicine. Time-resolved 3-dimensional magnetic resonance velocity mapping at $3 \mathrm{~T}$ reveals drastic changes in flow patterns in a partially thrombosed aortic arch. Circulation 113(11):e460-e461

Frydrychowicz A, Weigang E, Langer M, Markl M (2006b) Flowsensitive $3 \mathrm{~d}$ magnetic resonance imaging reveals complex blood flow alterations in aortic dacron graft repair. Interact Cardiovasc Thorac Surg 5:340-342

Frydrychowicz A, Harloff A, Jung B, Zaitsev M,Weigang E, Bley TA, Langer M, Henning J, Markl M (2007) Time-resolved 3D MR flow analysis at 3T: visualization of normal and pathological aortic vascular hemodynamics. J Comput Assist Tomogr 31(1):9-15

Gaehtgens P, Wayland H, Meiselman HJ (1971) Velocity profile measurements in living microvessels by a correlation method. In: Hartert H, Copley AL (eds) Theoretical and clinical hemorheology. The International Society of Hemorheology, Springer, University of Heidelberg, West Germany, pp 381-384

Gill RW (1985) Measurement of blood flow by ultrasound: accuracy and sources of error. Ultrasound Med Biol 11(4):625-641

Goodman JW (2000) Statistical optics. Wiley Classics Library, Wiley, New York

Harkness J (1971) The viscosity of human blood plasma; its measurement in health and disease. Biorheology 8(3):171-193

Hecht E (2002) Optics, 4th edn. Addison-Wesley, Reading

Hitt DL, Lowe ML, Tincher JR, Watters JM (1996) A new method for blood velocimetry in the microcirculation. Microcirculation 3(3):259-262

Hoeks AP, Reneman RS, Peronneau PA (1981) A multigate pulsed doppler system with serial data processing. IEEE Trans Son Ultrason SU-28(4):242-247

Horn BKP, Schunck BG (1981) Determining optical flow. Artif Intell 17:185-203

Hove JR (2004) In vivo biofluid dynamic imaging in the developing zebrafish. Birth Defects Res C Embryo Today 72(3):277-289

Hove JR, Köster RW, Forouhar AS, Acevedo-Bolton G, Fraser SE, Gharib M (2003) Intracardiac fluid forces are an essential epigenetic factor for embryonic cardiogenesis. Nature 421:172177

Hung TC, Hung TK, Bugliarello G (1979) Blood flow in straight and curved capillary glass tubes. J Biomech 12(12):945-947

Hung TC, Hung TK, Bugliarello G (1980) Blood flow in capillary tubes: curvature and gravity effects. Biorheology 17:331-342

Jeong JH, Sugii Y, Minamiyama M, Takeuchi H, Okamoto K (2007) Interaction between liposomes and $\mathrm{RBC}$ in microvessels in vivo. Microvasc Res 73(1):39-47

Ji L, Danuser G (2005) Tracking quasi-stationary flow of weak fluorescent signals by adaptive multi-frame correlation. J Microsc 220(Pt 3):150-167

Keane RD, Adrian RJ (1990) Optimization of particle image velocimeters. Part I: Double pulsed systems. Meas Sci Technol $1: 1202-1215$

Keane RD, Adrian RJ (1991) Optimization of particle image velocimeters. Part II: Multiple pulsed systems. Meas Sci Technol 2:963-974 
Keane RD, Adrian RJ (1992) Theory of cross-correlation analysis of PIV images. Appl Sci Res 49:191-215

Keane RD, Adrian RJ, Zhang Y (1995) Super-resolution particle imaging velocimetry. Meas Sci Technol 6:754-768

Kim HB, Hertzberg J, Lanning C, Shandas R (2004a) Noninvasive measurement of steady and pulsating velocity profiles and shear rates in arteries using echo PIV: in vitro validation studies. Ann Biomed Eng 32(8):1067-1076

Kim HB, Hertzberg JR, Shandas R (2004b) Development and validation of echo PIV. Exp Fluids 36:455-462

Kleiber M (1932) Body size and metabolism. Hilgardia 6:315-353

Levine H (1997) Rest heart rate and life expectancy. J Am Coll Cardiol 30(4):1104-1106

Ley K (1993) Molecular mechanisms of leucocyte rolling and adhesion to microvascular endothelium. Eur Heart J 14(Suppl I):68-73

Liepsch DW (1986) Flow in tubes and arteries-a comparison. Biorheology 23:395-433

Liepsch D (2002) An introduction to biofluid mechanics-basic models and applications. J Biomech 35(4):415-435

Lin BA, Einav S, Zarandi MM, Gharib M (2003) Digital ultrasound speckle image velocimetry for quantitative cardiovascular flow visualization. In: 5th International Symposium on Particle Image Velocimetry, Busan, Korea, Paper 3152

Lindken R, Westerweel J, Wieneke B (2006) Stereoscopic micro particle image velocimetry. Exp Fluids 41:161-171

Lipowsky HH (2005) Microvascular rheology and hemodynamics. Microcirculation 12(1):5-15

Lodge MA, Braess H, Mahmoud F, Suh J, Englar N, Geyser-Stoops S, Jenkins J, Bacharach SL, Dilsizian V (2005) Developments in nuclear cardiology: transition from single photon emission computed tomography to positron emission tomography-computed tomography. J Invasive Cardiol 17(9):491-496

Long DS, Smith ML, Pries AR, Ley K, Damiano ER (2004) Microviscometry reveals reduced blood viscosity and altered shear rate and shear stress profiles in microvessels after hemodilution. Proc Natl Acad Sci USA 101(27):10060-10065

Lucas B, Kanade T (1981) An iterative image registration technique with an application to stereo vision. In: International Conference on Artificial Intelligence, pp 674-679

Männer J (2000) Cardiac looping in the chick embryo: a morphological review with special reference to terminological and biomechanical aspects of the looping process. Anat Rec 259:248-262

Markl M, Chan FP, Alley MT, Wedding KL, Draney MT, Elkins CJ, Parker DW, Wicker R, Taylor CA, Herfkens RJ, Pelc NJ (2003) Time-resolved three-dimensional phase-contrast MRI. J Magn Reson Imaging 17(4):499-506

McMahon T, Bonner J (1983) On Size and Life. Scientific American Library

Meinhart CD, Wereley ST, Santiago JG (1999) PIV measurements of a microchannel flow. Exp Fluids 27:414-419

Meinhart CD, Wereley ST, Gray MHB (2000a) Volume illumination for two-dimensional particle image velocimetry. Meas Sci Technol 11:809-814

Meinhart CD, Wereley ST, Santiago JG (2000b) A PIV algorithm for estimating time-averaged velocity fields. J Fluid Eng 122:285-289

Merzkirch W (1987) Flow visualization. Academic Press, San Diego

Merzkirch W (2004) Fluid mechanics of flow metering. Springer, Heidelberg

Michelson G, Groh M, Langhans M, Schmauss B (1995) 2dimensional mapping and retinal and papillary microcirculation using scanning laser Doppler flowmetry (german language article). Klin Monatsbl Augenh 207(3):180-190

Monro PAG (1965) Visual particle velocity measurements in fluid streams. In: Copley A (ed) Symposium on biorheology, pp 439449
Murray CJ, Lopez AD (1997) Mortality by cause for eight regions of the world: global burden of disease study. Lancet 349(9061):1269-1276

Nezafat R, Kellman P, Derbyshire JA, McVeigh ER (2005) Real-time blood flow imaging using autocalibrated spiral sensitivity encoding. Magn Reson Med 54(6):1557-1561

Nyquist H (1928) Certain topics in telegraph transmission theory. Proc IEEE 47:617-644

Olsen MG, Adrian RJ (2000) Out-of-focus effects on particle image visibility and correlation in microscopic particle image velocimetry. Exp Fluids 29(7):166-174, suppl.

Pape SA, Skouras CA, Byrne PO (2001) An audit of the use of laser Doppler imaging (LDI) in the assessment of burns of intermediate depth. Burns 27(3):233-239

Popel AS, Johnson PC (2005) Microcirculation and hemorheology. Annu Rev Fluid Mech 37:43-69

Powell AJ, Geva T (2000) Blood flow measurement by magnetic resonance imaging in congenital heart disease. Pediatr Cardiol 21:47-58

Prasad AK (2000) Stereoscopic particle image velocimetry. Exp Fluids 29:103-116

Pries AR, Neuhaus D, Gaehtgens P (1992) Blood viscosity in tube flow: dependence on diameter and hematocrit. Am J Physiol 263(6 Pt 2):H1770-H1178

Raffel M, Willert C, Kompenhans J (1998) Particle image velocimetry: a practical guide. Springer, Heidelberg

Reneman RS, Arts T, Hoeks APG (2006) Wall shear stress-an important determinant of endothelial cell function and structure-in the arterial system in vivo. discrepancies with theory. J Vasc Res 43(3):251-269

Santiago JG, Wereley ST, Meinhart CD, Beebe DJ, Adrian RJ (1998) A particle image velocimetry system for microfluidics. Exp Fluids 25:316-319

Schmid-Schoenbein GW, Zweifach BW (1975) RBC velocity profiles in arterioles and venules of the rabbit omentum. Microvasc Res 10(2):153-164

Schmidt R, Thews G (eds) (1987) Human physiology. Springer, Heidelberg

Serov A, Steenbergen W, de Mul F (2002) Laser Doppler perfusion imaging with a complimentary metal oxide semiconductor image sensor. Opt Lett 27(5):300-302

Serov A, Steinacher B, Lasser T (2005) Full-field laser Doppler perfusion imaging and monitoring with an intelligent CMOS camera. Opt Express 13(10):1681-1689

Shirai K, Pfister T, Büttner L, Czarske J, Müller H, Becker S, Lienhart H, Durst F (2006) Highly spatially resolved velocity measurements of a turbulent channel flow by a fiber-optic heterodyne laser-doppler velocity-profile sensor. Exp Fluids 40:473-481

Shul'man ZP, Markova LV, Makhanek AA (1995) Rheological factor and Fahraeus-Lindquist effect. J Eng Phys Thermophys 68(3):353-363

Singer JR (1959) Blood flow rates by nuclear magnetic resonance imaging. Science 130:1652-1653

Singer JR, Crooks LE (1983) Nuclear magnetic resonance blood flow measurements in the human brain. Science 221(4611):654-656

Singh M, Prakash B (1994) Analysis of blood flow field in glass capillaries and in vivo microvessels by axial tomographic and image velocimetry techniques. In: Liepsch D (ed) VDI-Fortschrittsberichte, vol 17. VDI Verlag, Munich, Germany, Biotechnik, pp 239-253

Singh AK, Cummings EB, Throckmorton DJ (2001) Fluorescent liposome flow markers for microscale particle-image velocimetry. Anal Chem 73(5):1057-1061

Slaaf DW, Tangelder GJ, Reneman RS (1984) Rheological behavior of blood platelets in vivo. Biorheology 1(Suppl.):145-149 
Smith MA (1990) The measurement and visualisation of vessel blood flow by magnetic resonance imaging. Clin Phys Physiol Meas 11(2):101-123

Smith ML, Long DS, Damiano ER, Ley K (2003) Near-wall microPIV reveals a hydrodynamically relevant endothelial surface layer in venules in vivo. Biophys J 85(1):637-645

Sperandio M, Pickard J, Unnikrishnan S, Acton ST, Ley K (2006) Analysis of leukocyte rolling in vivo and in vitro. Methods Enzymol 416:346-371

Sugii Y, Nishio S, Okamoto K (2002a) In vivo PIV measurement of red blood cell velocity field in microvessels considering mesentery motion. Physiol Meas 23(2):403-416

Sugii Y, Nishio S, Okamoto K (2002b) Measurement of a velocity field in microvessels using a high resolution PIV technique. Ann N Y Acad Sci 972:331-336

Tabrizchi R, Pugsley MK (2000) Methods of blood flow measurement in the arterial circulatory system. J Pharmacol Toxicol Methods 44(2):375-384

Tangelder GJ, Teirlinck HC, Slaaf DW, Reneman RS (1985) Distribution of blood platelets flowing in arterioles. Am J Physiol 248(3 Pt 2):H318-H323

Tangelder GJ, Slaaf DW, Muijtjens AM, Arts T, oude Egbrink MG, Reneman RS (1986) Velocity profiles of blood platelets and red blood cells flowing in arterioles of the rabbit mesentery. Circ Res 59(5):505-514

Tangelder GJ, Slaaf DW, Arts T, Reneman RS (1988) Wall shear rate in arterioles in vivo: least estimates from platelet velocity profiles. Am J Physiol 254(6 Pt 2):H1059-H1064

Tropea C (1995) Laser doppler anemometry: recent developments and future challenges. Meas Sci Technol 6:605-619

Tsukada K, Minamitani H, Sekizuka E, Oshio C (2000) Image correlation method for measuring blood flow velocity in microcirculation: correlation 'window' simulation and in vivo image analysis. Physiol Meas 21(4):459-471

Uijttewaal WS, Nijhof EJ, Bronkhorst PJ, Den Hartog E, Heethaar RM (1993) Near-wall excess of platelets induced by lateral migration of erythrocytes in flowing blood. Am J Physiol 264(4 Pt 2):H1239-1244

Uijttewaal WS, Nijhof EJ, Heethaar RM (1994) Lateral migration of blood cells and microspheres in two-dimensional Poiseuille flow: a laser-Doppler study. J Biomech 27(1):35-42

Vennemann P, Kiger KT, Lindken R, Groenendijk BCW, Stekelenburg-de Vos S, ten Hagen TLM, Ursem NTC, Poelmann RE,
Westerweel J, Hierck BP (2006a) In vivo micro particle image velocimetry measurements of blood-plasma in the embryonic avian heart. J Biomech 39:1191-1200

Vennemann P, Lindken R, Hierck BP, Westerweel J (2006b) Volumetric particle image velocimetry in the developing chicken heart. J Biomech 39(Suppl 1):S616

Völker AC, Zakharov P, Weber B, Buck A, Scheffold F (2005) Laser speckle imaging with an active noise reduction scheme. Opt Express 13:9782-9787

Wårdell K, Jakobsson A, Nilsson G (1993) Laser Doppler perfusion imaging by dynamic light scattering. IEEE Trans Biomed Eng 40(4):309-316

Wang CY, Bassingthwaighte JB (2003) Blood flow in small curved tubes. J Biomech Eng 125(6):910-913

Wayland H (1967) Rheology and the microcirculation. Gastroenterology 52(2):342-355

Westerweel J (1997) Fundamentals of digital particle image velocimetry. Meas Sci Technol 8:1379-1392

Westerweel J, Geelhoed PF, Lindken R (2004) Single-pixel resolution ensemble correlation for micro-PIV applications. Exp Fluids 37(3):375-384

Woodle MC, Lasic DD (1992) Sterically stabilized liposomes. Biochim Biophys Acta 1113(2):171-199

Yuan S, Devor A, Boas DA, Dunn AK (2005) Determination of optimal exposure time for imaging of blood flow changes with laser speckle contrast imaging. Appl Opt 44(10):1823-1830

Zamir M, Ritman EL (2000) The physics of Pulsatile flow. American Institute of Physics

Zhao H, Webb RH, Ortel B (2002) Review of noninvasive methods for skin blood flow imaging in microcirculation. J Clin Eng 40(1):40-47

Zheng H, Mukdadi O, Kim H, Hertzberg JR, Shandas R (2005) Advantages in using multifrequency excitation of contrast microbubbles for enhancing echo particle image velocimetry techniques: initial numerical studies using rectangular and triangular waves. Ultrasound Med Biol 31(1):99-108

Zheng H, Liu L, Williams L, Hertzberg JR, Lanning C, Shandas R (2006) Real time multicomponent echo particle image velocimetry technique for opaque flow imaging. Appl Phys Lett $88: 261,915(1)-261,915(3)$ 